\title{
EXPLORAÇÃO DO TRABALHO INFANTIL, ESPAÇO URBANO E SINAIS DE TRÂNSITO: TENSÕES ENTRE SER CRIANÇA E TER QUE TRABALHAR
}

\author{
Túlio Campos ${ }^{1}$ \\ Walter Ernesto Ude Marques ${ }^{2}$
}

Resumo: Este texto tem como objetivo fomentar discussões relativas à exploração do trabalho infantil no contexto urbano, bem como suas implicações no que diz respeito às tensões entre ser criança e ter que trabalhar, visando problematizar as condições da presença de uma determinada infância, a infância trabalhadora na metrópole, em especial, a dos "sinais" de trânsito. Busca também levantar questões referentes à rua como espaço de afirmação da virilidade, a qual se apresenta marcada por códigos e delimitações temporais próprios de um etos guerreiro, composto por trabalhadores infanto-juvenis masculinos.

Palavras-chave: Infância. Trabalho. Exploração do trabalho infantil. 


\section{Introdução}

Levantar questões acerca da exploração do trabalho infantil não representa uma tarefa que possa ser tratada de uma maneira simplista. No que tange à temática, encontramos situações aviltantes que usurpam da mão-de-obra infanto-juvenil, como meio de extrair lucratividade no sistema capitalista, em diversos países, nos quais estão envolvidos fatores de natureza política, ética, estética, cultural, histórica, econômica e de organização social.

Atualmente, destacamos que as circunstâncias da infância empobrecida no Brasil e no mundo, tornam-se preocupantes devido à crescente precariedade social de grande parte da população mundial, desencadeada pelo expressivo aumento da concentração de renda de maneira globalizada. O neoliberalismo e a nova ordem econômica vêm acarretando uma série de consequências alarmantes na vida dos sujeitos. Mesmo com os constantes anúncios do crescimento da economia brasileira, apregoado por meio do Produto Interno Bruto (PIB), nas últimas décadas, ainda é expressiva as profundas mutações no mundo do trabalho, dentre as quais podemos inicialmente destacar a precarização dos postos de trabalhos, o aumento do desemprego e do subemprego, a degradação dos direitos trabalhistas, dentre outros, o que agrava ainda mais a condição de vida da maioria da população.

$\mathrm{Na}$ vida cotidiana avaliamos que este contexto atual tem gerado embrutecimento das relações sociais, em decorrência da forma assumida pela expansão capitalista, como pode ser averiguado nos infindáveis e espantosos quadros de violência expressos nas diversas linguagens midiáticas. Concomitantemente, observa-se a crescente fragilização dos laços conjugais, a explosão urbana com todas as dificuldades decorrentes de viver em grandes cidades, a valorização da vida privada, a globalização cultural, entre outros. Nesse aspecto, a informalidade toma conta das relações pessoais e as ações dos sujeitos são transformadas em atos banais, efêmeros, familiares e até triviais (OLIVEIRA, 2004, CARLOS, 2001).

No caso do Brasil, em decorrência dos intensos processos de urbanização ocorridos entre as décadas de 50 e 80, muitas cidades brasileiras ganham um novo formato, ou seja, a de metrópoles 
(SEABRA, 2004; CARLOS, 2001). Tudo isso implicou e implica em novas práticas de ocupação dos tempos e espaços das metrópoles, principalmente pelas crianças. Os usos e apropriações dos tempos e espaços da cidade são realizadas de diferentes formas pelas crianças, seja como lugar de encontro, espaço de comunicação, espaço de visibilidade social, espaço de brincadeiras, do trabalho, dentre outras possibilidades (DEBORTOLI et al, 2008).

Nessa perspectiva, este texto tem como objetivo fomentar discussões relativas à exploração do trabalho infantil no contexto urbano, bem como suas implicações no que diz respeito às tensões entre ser criança e ter que trabalhar, visando problematizar as condições da presença de uma determinada infância, a infância trabalhadora na metrópole, em especial, a dos "sinais" de trânsito. Busca também levantar questões referentes à rua como espaço de afirmação da virilidade, a qual se apresenta marcada por códigos e delimitações temporais próprios de um etos guerreiro, composto por trabalhadores infanto-juvenis masculinos.

Neste trabalho optou-se por adotar o termo "exploração do trabalho infantil", em consonância com as observações apontadas por Silva (2007), já que existe, ainda, no senso comum, tanto na academia, nas instituições e órgãos oficiais, bem como, na mídia e na população em geral concernente à temática, uma idéia de que todo trabalho infantil é explorado, sem uma análise mais crítica das atividades realizadas pelas crianças no contex to do trabalho. Nesse aspecto, temos que debater a distinção necessária entre trabalho educativo e trabalho explorado. Dessa forma, consagram certa "confusão conceitual, etimológica, epistemológica e ideológica, podendo, até mesmo, incidir e influenciar a produção de políticas públicas" (p. 57).

O mesmo autor indica que a maioria das produções acadêmicas se posiciona criticamente contra o trabalho precoce, na perspectiva do campo e da cidade. Diversas áreas do conhecimento - dentre elas a maior parte de estudos concentrados nas Ciências Humanas e Sociais - abordam a temática, a propósito de debaterem os aspectos históricos, demográficos, políticos, jurídicos, econômicos e culturais da exploração do trabalho infantil, elencando questões das possíveis consequiências na escolarização das crianças, no desenvolvimento biopsicossocial e na supressão do direito ao tempo do lúdico. Todavia, salvo raras 
exceções, grande parte dos estudos "refere-se à categoria do trabalho infantil, não diferenciando-a da exploração do trabalho infantil" (SILVA, 2007, p. 67).

Nessa linha de pensamento, quando se fala em trabalho infantil, este pode ser "confundido com qualquer tipo de 'trabalho de crianças', como por exemplo, o "trabalho como princípio educativo"” (p. 61). A exploração do trabalho infantil não se constitui num trabalho educativo, cujo processo deve sempre satisfazer uma necessidade social e encarnar o tempo de trabalho socialmente necessário (SILVA, 2001). Nesse aspecto, cabe destacar Oliveira (1994, p. 20): "Quando o trabalho de crianças faz parte real do processo de socialização e constitui um meio de transmissão de conhecimentos e experiências de pais para filhos, faz pouco sentido falar de trabalho infantil".

Neste sentido, entende-se por trabalho educativo, segundo Oliveira (1996, p. 22), a "atividade mediadora dentro da prática social, como um fator imprescindível do processo de passagem do ser ao dever-ser, um processo de transformação social".

Diante de tais considerações, faz-se necessário interrogar a respeito do cotidiano dos pequenos trabalhadores, sobretudo, aqueles que estão situados nos grandes centros urbanos.

\section{Breve Contextualização do Problema: urbanização, industrialização e tempo e espaço na metrópole}

Diferentes fatos sociais, econômicos, políticos, históricos e culturais ocorridos na Europa, principalmente no século XIX, trouxeram consequências, que atualmente, causam inquietações e indignações frente às transformações que vêm ocorrendo no mundo contemporâneo e seus efeitos sobre a vida, a cultura, o trabalho e as relações sociais.

Os processos de urbanização e industrialização caracterizam-se por ocorrências que mudaram o modo de vida de grande parte da população mundial. A modernidade, emblemática com o surgimento das "inovações talismânicas", tais como: o telégrafo e o telefone, as estradas de ferro e o automóvel, a fotografia e o cinema, inaugura novas formas de comércio e atividades econômicas.

Munford (1961), relacionando os processos de industrialização e migração ocorridos no mundo, destaca que até o século XIX havia um 
equilíbrio de atividades dentro da cidade. As atividades agrícolas, frente à modernização, começam a perder espaços de atuação e como forma de subsistência do ser humano, o qual se vê atraído pelo sentimento de ascensão às novas tecnologias. A expansão das relações assalariadas modifica o viver nas cidades modernas, proporcionando novos espaços de circulação dos corpos e das mercadorias.

$\mathrm{O}$ mesmo autor aponta que talvez o fato mais importante seja o deslocamento da população ocorrido em todo o planeta, tendo como consequiência a espantosa ascensão no índice de crescimento demográfico, que teve como ponto de partida causas industriais e comerciais.

O desenvolvimento do capitalismo, em escala planetária, desencadeou um processo de acumulação de capital e de mercadorias obstinado a lucrar a partir de posições desiguais de relação de produção, ocasionando uma nova divisão internacional do mundo do trabalho. As inovações tecnológicas possibilitaram o fornecimento e produção de mercadorias em qualquer lugar do mundo. Todavia, os países pertencentes ao denominado de "Terceiro Mundo" tornaram-se alvo de exploração de mão-de-obra barata para a produção final de mercadorias.

Segundo Graciani (2005), todo esse novo processo constitui-se como fato causador da divisão social da população, no qual temos, de um lado, os detentores do poderio do capital, técnicos especializados, negociantes, e até mão-de-obra especializada e, de outro, a mão-de-obra não especializada, gerando quadros infindáveis de extração de lucro a qualquer custo. Com o passar dos anos, os processos da panacéia capitalista se intensificam e se fortalecem , atingindo grande parte da população mundial que se encontra no final do processo de exploração e exclusão.

Nesse aspecto, Santos (2002) destaca que as duas primeiras décadas do período republicano no Brasil representaram um importante marco histórico da urbanização e da industrialização de São Paulo. Com o fim do regime escravista e a entrada maciça de mão-de-obra imigrante ocorre uma profunda transformação na cidade. Em decorrência da dinamização e diversificação da economia a cidade se desenvolve e afirma-se como grande mercado distribuidor e centro de integração regional. Posteriormente, outras cidades também se avolumam, surgindo novas formas de viver na cidade. Entretanto, os investimentos na agricultura se tornam reduzidos. 
No Brasil a migração do campo para a cidade, se transformou numa das mais expressivas mudanças na estrutura social. De acordo com Santos (1994), a remodelação do território nacional foi obtida a partir do desenvolvimento do chamado meio técnico-científico ${ }^{3}$. O autor destaca que o principal motor desse processo social se deu nos meios da informação, já que se passou a ser sinônimo de progresso econômico e social e, conseqüentemente, tudo foi feito para facilitar a sua circulação. Nesse sentido, num espaço de tempo relativamente curto, o Brasil acelerou a mecanização do território, consubstanciando novas formas de integração territorial, aplicando alguns investimentos nas estradas de rodagem, principalmente após a segunda guerra mundial.

Outro marco histórico fundamental, nesse processo, foi a configuração do golpe de Estado de 64. O movimento militar criou as condições de uma rápida integração do País a um movimento de internacionalização. Com o aumento da população, com a ampliação da classe média e com a sedução por um consumo diversificado de mercadorias, a expansão industrial se impulsiona, concentrando atividades modernas e dinâmicas. Logo, a economia se desenvolve para atender a um mercado consumidor em notável expansão e, também, busca responder a uma demanda exterior. Nesse sentido, Santos (1994) afirma que todo esse movimento construiu bases de uma verdadeira fluidez do território, ao comentar que o "espaço torna-se fluído, permitindo que os fatores de produção, o trabalho, os produtos, as mercadorias, o capital, passem a ter uma grande mobilidade.” (p. 39).

Nesse sentido, Graciani (2005) destaca que todo este contexto de mudança corresponde a uma ruptura anterior com forças sociais de convivência, significando um processo forçado e compulsório. Segundo a autora, entre 1940 e 1980, dá-se uma verdadeira inversão quanto ao lugar de residência da população. A taxa de urbanização em 1940 era de 26,54\% e em 1980 passa a ser de 68,86\%. Nesse período, a população urbana se multiplica por sete vezes e meia (SANTOS, 1994).

O êxodo rural provocou o aparecimento dos grandes centros urbanos, onde as pessoas, expulsas do campo por uso da força dos latifundiários ou indiretamente pela falta de condições de continuar a ser um pequeno agricultor, chegam sem preparo para lidar com as novas formas de produção e com a vida diferente do campo. Dessa 
forma, são obrigadas a adaptarem-se às formas de inserção provisória em diversos espaços, sem o mínimo de segurança e, não raro, privadas de levar uma vida digna.

A modernização generalizada beneficia a divisão social do trabalho, favorecendo o êxodo rural. No meio agrícola, a influência de complexos agroindustriais determinou novas formas de produzir, impondo ao setor a adoção de tecnologias mais modernas e mais rentáveis. Segundo Marin (2006), a desvalorização da força de trabalho, a não garantia dos direitos previdenciários e trabalhistas e o aviltamento dos salários, se deu concomitantemente a um processo simultâneo às transformações tecnológicas desencadeadas na agricultura. Tais transformações provocaram a expulsão de grandes contingentes populacionais do campo que, na esperança de conquistarem uma vida melhor, vão buscar nas cidades outros modos de sobreviver.

Nesta nova conjuntura, na qual a industrialização exige poucos trabalhadores qualificados e muitos outros com pouca ou nenhuma qualificação para fornecerem e prepararem as matérias-primas, os migrantes submetem-se a quaisquer formas de trabalho para terem um mínimo de condições de sobrevivência nas áreas urbanas. Baixos salários e amplas jornadas fazem parte da rotina do novo habitante da cidade. De acordo com Martins (1993), o desenvolvimento acelerado dos países ricos implicou, diretamente nos países pobres, um intenso descarte de mão-de-obra barata, disseminando diferentes formas de trabalho clandestino.

Com o passar dos anos pode-se constatar que a presença de um cenário crítico, como o destacado acima, na sociedade contemporânea atinge não só os países do chamado Terceiro Mundo, como o Brasil, mas também os países capitalistas centrais, num processo que a cada dia o embrutecimento das relações trabalhistas toma proporções assustadoras (SILVA, 2007). Sem condições de sobreviverem nesse novo sistema de produção, as famílias se vêem obrigadas a inserir seus filhos no trabalho explorado. Nesse longo processo de mudança a presença das crianças no trabalho se fez de diferentes modos, tal como pretendemos apresentar no próximo item. 


\section{As crianças no cotidiano do trabalho explorado: aspectos histórico-jurídicos.}

A inserção precoce das crianças no trabalho ganha forma mais concreta, principalmente, a partir do surgimento do sentimento moderno, onde a consolidação do modo de produção capitalista molda e faz aparecer um novo conceito de ser humano, trabalhador incansável, sujeito competitivo e individualista ${ }^{4}$. De acordo com Campos \& Alverga (2001), a ética do trabalho se prestava à discriminação entre classes, na medida em que a burguesia comercial inglesa conduzia seus filhos ao trabalho intelectual, restando aos filhos das classes desprivilegiadas o ingresso prematuro ao mundo do trabalho fabril, agrícola, artesanal, dentre outros.

Nos primórdios da Revolução Industrial, o uso e a exploração da força de trabalho infantil estavam estreitamente associados ao desenvolvimento capitalista. O aprimoramento da maquinaria industrial reduziu o uso da força muscular e exigiu mais qualidades específicas no momento da produção. Neste momento, entram em cena os infantes ${ }^{5}$, já que eram considerados mais hábeis e ágeis para manusearem as máquinas, além de suportar mais o tempo de trabalho sem se queixar das árduas tarefas (MARIN, 2006; SANTOS, 2002).

Outro fator explicativo para o uso da força de crianças na indústria estava relacionado à redução dos custos de produção, uma vez que, não raro, elas recebiam baixíssimos salários e se submetiam a quaisquer imposições. Conseqüentemente em decorrência do maior número de mãode-obra disponível no mercado de trabalho, tal iniciativa implicou na redução salarial dos adultos. Não conseguindo prover os meios de sobrevivência, eles são obrigados a incorporar os filhos e as mulheres no trabalho. Nessa perspectiva, destaca Moura (2002, p. 262).

A exploração do trabalho se dava por meio da compressão salarial do trabalhador adulto de sexo masculino; da exploração da mãode-obra feminina, uma vez que a remuneração de meninas e de adolescente do sexo feminino caracterizava a dupla discriminação de sexo e de idade; e refletia claramente o fato de que sobre a infância e a adolescência pesava decisivamente a determinação do empresariado em reduzir os custos da produção. 
Nas fábricas o ambiente era degradante. A precariedade de ventilação e iluminação, espaços exíguos, ausência de dispositivos de segurança, liberação constante de partículas nocivas, odores e gases liberados pelas máquinas, a alimentação insuficiente e horas de trabalho ininterrupto faziam parte do dia-a-dia dos pequenos trabalhadores. Submetidas às condições de trabalho inadequadas à idade, diversas crianças, constantemente, sofriam acidentes. Mutilações, fraturas e queimaduras eram rotineiras. Além disso, também merecem destaque os ferimentos causados pelos maus-tratos aos pequenos operários, com objetivos de mantê-los em constante atenção, situação essa reveladora de extrema violência utilizada pelos patrões e representantes dos cargos de chefia. (MARIN, 2006; MOURA, 2002; RIZZINI, 2002).

Analisando a presença das crianças operárias na recém-industrializada São Paulo, Moura (2002) aponta que as relações humanas e de trabalho, nos estabelecimentos industriais da capital se davam em permanente tensão: brigas, agressões e desavenças eram constantes entre operários e patrões. Nem os pequenos trabalhadores escapavam das agressões.

A exploração do trabalho infantil só passou a ser debatida publicamente nas primeiras décadas do século XX, no início da industrialização brasileira. Os industriais, para atenuar as acusações que lhes eram impostas, argumentavam que os próprios pais queriam seus filhos no trabalho para contribuir com o orçamento familiar (MARIN, 2006). O discurso do patronato procurava esvaziar o sentido da problematização da exploração das crianças, incrementando ao discurso a aura moralizadora e disciplinadora do trabalho, e, também, apresentando-o como melhor alternativa para a chamada "marginalidade", "criminalidade", e "periculosidade" (MARIN, 2006; BULCÃO, 2002; MOURA, 2002; RIZZINI, 2002). Assim, como pondera Rizzini, é possível destacar que:

O trabalho da criança e do adolescente das classes populares é visto em nossa sociedade como mecanismo disciplinador, capaz de afastálos das companhias maléficas e dos perigos da rua. A 'escola do trabalho' é percebida como verdadeira 'escola da vida' (2002, p. 389).

Tendo em vista esses acontecimentos, os juristas ampliam um discurso de preocupação com a infância. Atentos ao crescente número de crianças 
nas ruas, a legislação começa a refletir sobre possíveis formas de educar a criança, em um discurso moralista de preservação das crianças e de preparação para o futuro. Assim, como destaca Bulcão (2002, p. 67) "notamos mais uma mudança na percepção da infância. A criança é vista como futuro cidadão, futuro do homem e da pátria, devendo ser normatizada de acordo com a nova ordem disciplinar vigente para ser útil e produtiva ao país". Todavia, a saída das crianças do universo da fabril provocou grandes embates, pois estavam em jogo múltiplos interesses econômicos, valores, tradições e concepções de mundo, defendidos por diversos atores sociais, tais como: industriais, membros das famílias, políticos, legisladores, médicos, educadores e religiosos, entre outros (MARIN, 2006).

Por meio da Lei Federal $n^{\circ} 1.597$, de 1917, e de outros decretos vigentes em âmbito estadual, estabelece-se a idade de 12 anos como limite para admissãono mundo do trabalho e normatizam algumas condições de trabalho, como exemplo, o Decreto Estadual no 2141/1911, na Lei Estadual $n^{\circ} 1596 / 1917$ e no decreto que vem sancioná-la em abril de 1918, a qual proíbe o trabalho noturno aos menores de 18 anos de idade (MOURA, 2002). Contudo, respaldada em um sistema de fiscalização imprecisa, inoperante e ineficiente, na maioria dos casos, essa legislação não conseguiu contemplar os interesses da classe trabalhadora e evitar que crianças e adolescentes continuassem submetidos aos constrangimentos no mundo do trabalho (MARIN, 2006; MOURA, 2002; OLIVEIRA, 1994).

O Decreto ${ }^{\circ}$ 17.343/A, de 12 de dezembro de 1927, conhecido como Código de Menores buscava organizar as formas de trabalho e normatização de uma infância em geral (MARIN, 2006; MOURA, 2002; CAMPOS \& ALVERGA, 2002). O decreto estabelecia a proibição do emprego de menores de 12 anos em todo território nacional, além de apontar outras restrições relacionadas aos locais e jornadas de trabalho, punições ou prisão para os infratores (MARIN, 2006; MOURA, 2002;).

A valorização positiva do trabalho na formação e reprodução das novas gerações fez com que, mesmo sob proteção jurídica, a criança e o adolescente permanecessem em espaços e condições aviltantes. Segundo Marin (2006), os movimentos operários investiram na denúncia pública contra o caráter desumano da exploração do trabalho infantil, apontandoo como causa do desemprego e do empobrecimento dos trabalhadores adultos, exigindo posturas mais eficientes por parte do poder público. Nesse 
sentido, afirma o autor que "de certa forma, a pressão do movimento operário colaborou para a promulgação, no início da década de 1930, de leis que procuravam prevenir a exploração da força de trabalho infantil" (MARIN, 2006, p. 20).

Diante do quadro social vivenciado pelas crianças e adolescentes, novas formas de se pensar a infância mobilizaram diversas ciências nas quais um discurso civilizador sustentava os debates. Nos dizeres de Arroyo (2008, p. 123), o objetivo principal dos saberes que vinham sendo construídos era "conformar a infância civilizada como padrão da modernidade". Nesse aspecto, Campos \& Alverga, (2002) destacam que as políticas exercidas aprofundavam a distinção entre "criança" e "menor", sobrepondo ao conteúdo autoritário uma perspectiva ideológica, que tentava oferecer as bases para o controle da juventude do país.

Nessa perspectiva, surgem dois conceitos para a infância: o termo "menor", na visão dominante, era composto por crianças de famílias pobres, que perambulavam livres pela cidade, tendo conduta marcada pela amoralidade e pela falta de decoro, sendo vinculadas a instituições como cadeia, orfanato, asilo e trabalha nas ruas para sobreviver, como também perambulava em bandos com companhias suspeitas. Distinto do anterior, o termo "criança" era associado às crianças bem vestidas e instruídas pela família e pela escola (BULCÃO, 2002; CAMPOS \& ALVERGA, 2001; RIZZINI, 1993, PASSETTI, 1991).

A partir do movimento operário e do conhecimento científico que vinha sendo construído sobre a infância passam-se a ter maiores cuidados e atenção às crianças e aos adolescentes. Com a consolidação da Constituição Federal de 1934 diversas normas protetivas do trabalho infanto-juvenil foram inseridas nos textos constitucionais, proibindo o ingresso no trabalho aos menores de 14 anos; o trabalho noturno aos menores de 16 e o trabalho insalubre aos menores de 18 anos (CASTRO \&CASTRO, 2006; MARIN, 2006).

Mesmo diante do esforço na elaboração dessas leis, o problema do uso da força de crianças e adolescentes persistia em grande escala. A imprecisão das leis, a falta de uma efetiva fiscalização e a crença no caráter moralizador do trabalho foram motivos suficientes para a permanência das crianças no mundo do trabalho. Tal perspectiva permaneceu durante décadas e só a partir da Constituição de 1988 é que ocorre um avanço significativo na questão da proteção e do cuidado da criança e do adolescente. 
Na esteira da constituição de 1988, o Estatuto da Criança e do Adolescente - ECA - Lei ${ }^{\circ}$ 8.069, de 13 de julho de 1990, procurou dispor sobre a proteção da criança e do adolescente (art. $1^{\circ}$ ). Nesse documento, o art. 60 determina que: "É proibido qualquer trabalho a menores de 16 (dezesseis) anos de idade, salvo na condição de aprendiz, a partir dos 14 (quatorze) anos"6. Nessa perspectiva, de acordo com a Lei, o termo trabalho infantil se refere às crianças e pré-adolescentes com idade abaixo de dezesseis anos que estão envolvidas no trabalho irregular sem possibilidades de desenvolver processos de aprendizagem que ofereçam qualificação profissional para um futuro mais digno (MARQUES, 2001).

Atualmente, considerado um problema mundial, a exploração do trabalho infantil é destaque também em diferentes órgãos internacionais. A Organização Internacional do Trabalho - OIT -, por meio da Convenção $138^{7}$, estabelece que todo Estado-membro, no qual vigore esta Convenção, especificará a idade mínima básica para o trabalho, que não seja inferior à idade de conclusão da escolaridade ou, em qualquer hipótese, não inferior a 15 anos. No entanto, nos países cuja economia e condições do ensino não estiverem suficientemente desenvolvidas, a idade mínima poderá ser fixada inicialmente em 14 anos.

Mesmo com os expressivos avanços tecnológicos e maiores destaques às leis e discussões sobre a problemática referente à presença da criança e do adolescente no mundo do trabalho, a exploração do trabalho infantil se faz presente em diversos setores produtivos, que vão desde a agricultura até a grande indústria, passando, também, pelos diferentes contextos sociais, como nos grandes centros urbanos. No Brasil, estima-se que os números ultrapassam os 5,1 milhões de crianças e adolescentes em situação de trabalho precoce, perigoso e insalubre.

Diante das questões postas acima, seguimos nosso debate sobre a presença do trabalho infantil no espaço urbano apresentando dados de alguns trabalhos que vem sendo desenvolvidos sobre a temática.

\section{Quanto às pesquisas relativas ao trabalho infantil na metrópole: a necessária qualificação dos dados quantitativos}

Em decorrência de ações lideradas pelo Fundo das Nações Unidas para a Infância (Unicef) e pela Organização Internacional do Trabalho 
- OIT, no contexto das quais balizam-se a luta em defesa da erradicação do trabalho infantil, as estatísticas revelam quedas dos número de crianças inseridas no trabalho explorado ${ }^{8}$. Todavia, outros estudos ${ }^{9}$ têm dado conta das renovadas formas de inserção de crianças e jovens neste tipo de atividade, quase nunca apontadas nas pesquisas realizadas pelos governos, de modo que se avalia de maneira crescente o número de pequenos trabalhadores e seus familiares em busca de estratégias para o complemento da renda familiar, conseqüientemente para tentar manter a sobrevivência do grupo (CAMPOS \& ALVERGA, 2001; MARIN 2006; MARQUES, 2001; RIZZINI, 2002).

Segundo Silva (2007), pode-se destacar o chamado "trabalho clandestino e invisível", quais sejam: casas de farinha, lixões, lavadores de carros, malabarismo e venda de balas nos semáforos das grandes e médias metrópoles, trabalho doméstico, sobretudo, feminino, dentre outras atividades ilícitas.

Os dados atuais fornecidos por diferentes órgãos demonstram que, mesmo com os esforços de diversos setores da sociedade e da legislação que visam sua erradicação, este problema ainda persiste em longa escala. De acordo com o mesmo autor, resultados encontrados em seus estudos indicam que há um "mito em torno da "erradicação do trabalho infantil"', por partes das políticas públicas, implementadas nos dois últimos governos do Brasil. Nessa perspectiva, destaca que:

As estatísticas, calcadas, em métodos unicamente quantitativos, apontam para uma suposta diminuição do 'trabalho infantil' e nem sempre da 'exploração do trabalho infantil' a partir dos 'efeitos' dos chamados programas de 'geração de renda', os quais têm caráter de política provisória, assistencialista e paternalista, cujo jargão (marketing político), propaga a 'inclusão social' e a aquisição de 'cidadania' (SILVA, 2007, s/p).

Toda a proibição e evidência das alarmantes consequências da exploração do trabalho infantil não têm sido suficientes para sanar o seu crescimento e o surgimento de novos casos em todo mundo. Segundo dados da PNAD 2007, as regiões Sudeste e Centro-Oeste apresentam o maior contingente de crianças e adolescentes, na faixa 
etária de 5 a 13 anos de idade, envolvidos em atividades não-agrícolas. Já nas outras regiões, na mesma faixa etária, o percentual é de $60,7 \%$ de ocupação em atividades agrícolas.

Em um trabalho ${ }^{10}$ realizado pela Gerência de Inserção Especial da Secretaria Municipal Adjunta de Assistência Social da Secretaria de Políticas Sociais da Prefeitura Municipal de Belo Horizonte foram identificados, no ano de 2004, 1.099 crianças e adolescentes em situação de trabalho nas ruas da metrópole. Segundo os dados, desses, 793 $(72,2 \%)$ residiam no município de Belo Horizonte, 296 (26,9\%) eram provenientes da Região Metropolitana e 10 (0,9\%) de outras cidades (SMAAS, 2004). Já no ano de 2006 foram constados 1.752 casos, sendo, 1.025 residiam na capital (59\%), 395 (23\%) na região Metropolitana, 12 (1\%) de cidades do interior e 319 (18\%) não informadas (SMAAS, 2006). Como se nota, houve um aumento 62,72\% entre os anos de 2004 e 2006.

No que diz respeito às atividades exercidas, destacam-se: vendedores ambulantes - 20,63\%; pedintes - 15,98\%; vigia e lava carros - 9,08\%; malabarismo - 6,69\%; distribuidor de panfletos - 6,22\%, entre outras. De acordo com Rocha (2006), dois fatores levam as crianças ao trabalho nas ruas: a necessidade de complementar a renda familiar e a crença que o trabalho é bom, ensina e fortalece.

Nesse aspecto, ao realizar um estudo ${ }^{11}$ entre os anos de 2005 e 2007 constatamos a presença de inúmeras crianças trabalhando em diferentes locais pela cidade de Belo Horizonte. Os pequenos trabalhadores foram observados, em distintos momentos do dia ou da semana, nos sinais de trânsito e em outros espaços como ruas, morros, praças, parques, transporte coletivo, feiras etc. Na pesquisa percebemos um aumento do número de crianças e adolescentes desempenhando diversas funções, tais como: vendedoras de balas ${ }^{12}$, catadoras de papel e latinhas, estátua viva ${ }^{13}$, vigias e lavadores de carros e malabaristas.

Outro fator de importante destaque foi que as crianças trabalhavam nas ruas em diferentes horários e dias da semana, abrangendo os finais de semana, feriados e também horários noturnos, sendo que alguns adentravam pela madrugada, em dias de grande necessidade financeira (CAMPOS \& DEBORTOLI, 2007; MARQUES, 2001). Junto a isso, estavam expostas as diversas situações de perigo que enfrentavam no 
seu cotidiano. Foram verificadas várias circunstâncias ameaçadoras que colocavam a dignidade pessoal e a vida em situações alarmantes, como: assédio sexual, furto, humilhação, brigas, atropelamentos, assalto, exploração sexual e seqüestros (CAMPOS \& DEBORTOLI, 2007; MARIN, 2006; MARQUES, 2001).

No presente momento, desenvolvemos um outro estudo ${ }^{14} \mathrm{com}$ crianças que estão no cotidiano do trabalho infantil, em especial, nos sinais de transito da cidade de Belo Horizonte. Em nossas observações, temos percebido que o universo das relações e a organização dos espaços e tempos que as crianças ocupam na cidade, durante o momento do trabalho, são geradores de constantes tensões. Muitas vezes se confundem com os espaços e tempos do brincar, da escola, do estar com a família, entre outras práticas.

Nas observações de campo e no encontro com as crianças a presença da brincadeira tem sido uma prática marcante no cotidiano do trabalho. Nesse sentido, bola de futebol, futebol de prego, brincadeiras de lutas, danças, cantigas, gírias, encenações e coreografias musicais, também, fazem parte do cotidiano das crianças nos semáforos. Ir ao local de trabalho, além da possibilidade de auferir dinheiro, representa, também, sinônimo de partilha de brincadeiras entre elas.

Qualquer objeto configura-se como brinquedo para as crianças e, assim, está em suas mãos decidir eleger, por meio da ação lúdica, os objetos que a ajudarão no processo de leitura do mundo (CAMPOS \& DEBORTOLI, 2007; GRACIANI, 2005; MARQUES, 2001). Pedaços de paus transformam-se em espadas e o coco vazio em bola de futebol. Tudo isso pode levá-las ao mundo do imaginário em lugares e mundos desconhecidos, conhecer pessoas e experimentar novas relações.

As tensões entre ser criança e ter que trabalhar geram relações paradoxais no cotidiano que se traduzem em práticas de resistência, liberdade e reivindicações por melhores condições de vida. Segundo Graciani, a crianças e adolescentes de/e na rua, quando brincam, realizam uma ação social transformadora que aponta para dois eixos: no primeiro, "nega-se a abdicar de sua participação na produção da cultura", no segundo, "nega-se a aceitar a discriminação sancionada pela sociedade capitalista, distinguindoe subordinando a atividade manual à atividade intelectual, quebrando a concepção classista que reafirma a condição social e a ocupação econômica” (2005, p. 156). 
Nesse contexto, tudo isso representa formas expressas de um saber construído no universo das relações entre os grupos de crianças, o qual se constitui a partir da criatividade, da imaginação, da inventividade e da capacidade interpretativa nas relações com outros sujeitos (CAMPOS \& DEBORTOLI, 2007, MARQUES, 2001). Nessa perspectiva, Silva pondera que:

O que realmente está em jogo, no meu entendimento, é o fato de elas brincarem numa realidade destruída pela racionalidade capitalista e, mesmo assim, se imporem como seres sociais, resistindo ludicamente, anunciando, enfim, um outro projeto de sociedade. Isso significa dizer que o tempo exíguo para o lúdico também carrega consigo, dialeticamente, as marcas históricas da pobreza, da privação, do trabalho estranhado, do cerceamento, da justiça, da má distribuição da renda e da terra (2007, p.71).

Nessa perspectiva, observa-se que os espaços e tempos no cotidiano da metrópole são explorados, ocupados e/ou vivenciados de diferentes maneiras pelas crianças. A avidez pelo novo e, conseqüentemente, as mudanças nas cidades ocorrem hoje de forma acelerada. A metrópole passa a se movimentar em decorrência das mudanças no traçado das ruas e avenidas, necessidade imposta pela velocidade e pelo aumento do fluxo de carros, pelas estratégias de mercado imobiliário e pelas transformações nas leis de zoneamento, redefinindo constantemente os lugares (CARLOS, 2001; SEABRA, 2004).

Não obstante, a presença das crianças nos espaços da cidade anuncia, tensiona e reproduz formas de viver, não raro, regidas na luta contra uma vida de miséria, de violência, sempre em busca de dignidade e de "visibilidade". Por exemplo, a praça, aos olhos de muitos, construída para separar duas ruas ganha significado de novas amizades, de aprendizagens, de brincadeiras, de resistência, de liberdade e sobrevivência. Diante disso, no próximo tópico, levantamos algumas questões referentes à relação entre rua e virilidade no cotidiano dos pequenos trabalhadores dos semáforos pesquisados. 


\section{Trabalho Infantil nos Semáforos, Rua e Masculinidade: algumas reflexões acerca da virilidade dos pequenos trabalhadores}

Na experiência compartilhada, neste estudo, ficou evidente que a atividade realizada pelos pequenos trabalhadores nos semáforos da metrópole pesquisada se caracteriza como um território predominantemente masculino. Curiosamente, os grupos que participaram desta pesquisa são compostos apenas por meninos. Todavia, alguns estudos apontam que determinadas formas de exploração do trabalho infantil nas ruas da cidade envolvem, na sua maioria, crianças e adolescentes do sexo feminino (DIMENSTEIN, 1992). Diante disso, avaliamos que as relações de gênero que se estabelecem nestes contextos necessitam ser mais debatidas para que se tente compreender as tramas histórico-sociais que contribuem para a configuração desse fenômeno, no intuito de gerar intervenções mais pertinentes.

Nesse sentido, pretendemos levantar alguns aspectos observados durante o trabalho de campo que está sendo realizado, no intuito de tentar evidenciar a relação estabelecida entre rua e virilidade no âmbito do mundo do trabalho infantil executado nos sinais de trânsito. Esse diálogo se torna possível quando se constata que a construção social da masculinidade, desde os primórdios da Idade Média até a instalação da Modernidade, se pautou em dois pilares que foram colocados como definidores da identidade masculina patriarcal - ser trabalhador e guerreiro (OLIVEIRA, 2004). Ser trabalhador para prover a família e fornecer mão-de-obra para uma sociedade industrial que se expandia; e ser guerreiro para invadir territórios para enriquecer a própria pátria e defendê-la de possíveis invasores, tal como os portugueses e demais colonizadores se comportaram na América Latina, dentre outras regiões do planeta.

Essa concepção fomentada pela burguesia dominante engendrou visões dicotômicas entre homens e mulheres, ao instituir bipolaridades que caracterizam a masculinidade, entendida como ser ativo, destemido, corajoso, violento, honesto e trabalhador; e a feminilidade, vista como passiva, dócil, submissa, afetiva e doméstica, entre outras prescrições. Essa divisão de atribuições determinou a constituição de espaços masculinos e femininos, tornando-se a rua um etos masculino e casa um etos feminino. Nessa perspectiva machista, trabalhadores devem transitar pela rua em 
direção ao trabalho em busca do provimento familiar. Aqueles que buscam ociosidade nas ruas se tornam suspeitos de estar praticando vagabundagem. Entretanto, a rua pode se constituir como um lugar de trabalho em contraposição à busca de um tempo disponível para o entretenimento. No caso deste estudo, os pequenos trabalhadores dos semáforos se vêem nessa tensão entre ser criança e ter que trabalhar.

Todavia, a rua concebida como dimensão associada ao etos viril estabelece códigos de honra que devem ser respeitados entre trabalhadoresguerreiros (MACHADO, 2004), já que a transgressão de determinadas normas e fronteiras implica na convocação de um duelo. Dentro da lógica viril, um homem se torna macho quando consegue subjugar outro homem, tanto por meio da força física quanto simbólica. Nesse aspecto, nos semáforos pesquisados foram recorrentes as tensas disputas entre territórios ocupados por pequenos trabalhadores que se postavam como verdadeiros guerreiros em defesa dos seus espaços de sobrevivência conquistados, sempre perante uma pequena platéia de colegas. A tentativa de apossar de um espaço ocupado por outro membro viril representa fato grave, considerando que fere as demarcações inscritas no etos da rua, podendo gerar uma guerra entre os defensores dos territórios delimitados. Não é à toa que, na nossa cultura, é comum ouvir dos trabalhadores, nos distintos ciclos etários, quando vão se referir à marcha para o seu local de trabalho utilizar frases como: "Estou indo ralar" (na guerra); "Vou batalhar"; "Sou guerreiro, estou indo trabalhar", dentre outras.

Essas representações da cultura viril, associadas ao etos guerreiro, compõem o imaginário da rua, afetando a subjetividade dos pequenos trabalhadores que atuam nos semáforos da metrópole. Nesse contexto, a denominada zoação constitui uma atividade muito presente entre esse público, no sentido de utilizar-se de chacotas, zombarias e gozeiras para tentar subjugar o Outro, visto como possível oponente. Essa configuração se instala por meio de relações assimétricas que procuram sustentar uma hierarquia mantida às custas de poder, potência e posse (OLIVEIRA, 2004). De acordo com Nogueira (2006), num estudo desenvolvido no ambiente escolar, essa postura falocêntrica dos meninos produz um protagonismo masculino constante que tenta se legitimar utilizando-se do artifício da zoação. Obviamente, que este expediente indica outros elementos constitutivos do universo simbólico e material da realidade que compartilham. 
Essas disputas se misturam também com a competitividade própria de um sistema capitalista, muito marcado pela lógica patriarcal, o qual propaga que o aumento da produtividade e da lucratividade se traduz em probabilidade de maior capacidade de consumo de mercadorias. Nesse sentido, os pequenos trabalhadores dos sinais de trânsito da cidade competem entre a ocupação de espaços territoriais para tentar auferir maior volume de dinheiro. A demonstração dessa capacidade representa a agregação de capital simbólico (BOURDIEU, 2003) no campo da dominação masculina. Por outro lado, a tentativa de roubar dinheiro do colega é punida por todos com rigor e censura, tendo em vista que desrespeita os códigos de honra da virilidade. Como se sabe, um verdadeiro trabalhador é um homem honesto e quando lesado aciona seu etos guerreiro. Essas premissas constituem a subjetividade masculina instalada na nossa cultura, as quais se manifestam nas permanentes tensões e reações violentas observadas no nosso cotidiano. Todavia, não podemos banalizá-las, mas problematizá-las, com o objetivo de procurar reduzir o quadro de violência verificado no mundo atual.

No que se refere à sexualidade, as brincadeiras entre os pequenos trabalhadores são freqüentes, configurando-se por meio de gestos e objetos que, metaforicamente, simbolizam desejos e fantasias que compõem a sua vida cotidiana. A erotização de acenos e movimentos corporais, dentre outras manifestações, revela o campo relacional desses sujeitos que entre si recorrem a zoações em torno dessa temática, aproveitando cenas dos transeuntes ou de expressões que acontecem no próprio grupo. Contudo, essas atividades se tornam marcadas pelo etos viril quando tentam afirmar a própria masculinidade e questionam a virilidade do colega. Nesse ponto, o caráter homofóbico presente na nossa cultura machista, se manifesta de diversas formas, seja de uma maneira explícita ou velada. Essas observações denotam a complexidade do fenômeno aqui debatido.

Como se observa, apesar de algumas mudanças geradas pelo movimento feminista, desde a década de 1960, ainda constatamos a presença da construção social e histórica de um etos viril associado à violência e à dominação, ancorado nos pilares da guerra e do trabalho explorado. Nesse cenário, fatores econômicos compõem essa realidade 
material e simbólica. Um homem desempregado se vê extremamente abatido quando não consegue executar sua tarefa de provedor, reagindo, muitas vezes, de maneira violenta perante a sociedade. Essas prescrições identitárias necessitam ser questionadas com veemência por pesquisadores e educadores sociais. As discussões acerca da identidade masculina são escassas, tanto no âmbito acadêmico quanto no bojo dos movimentos sociais. A realidade da exploração do trabalho infantil deve ser debatida na sua complexidade, não se reduzindo aos semáforos, apesar de passar por estes territórios metropolitanos. Existe toda uma trama complexa que necessitamos tentar compreender que, dentre outros elementos, traz dimensões das relações de gênero construídas no contexto histórico-cultural que compartilhamos.

Diante disso, esperamos que essa breve discussão possa contribuir para a inclusão dessa temática na pauta dos debates acerca da exploração da mão-de-obra infanto-juvenil. Além disso, percebemos a necessidade de novos estudos, nos quais o quantitativo seja qualificado na complexidade, na tentativa de contribuir para a formulação de políticas públicas mais abrangentes para o enfrentamento deste fenômeno.

\section{Notas}

${ }^{1}$ Licenciado em Educação Física - Escola de Educação Física, Fisioterapia e Terapia Ocupacional da Universidade Federal de Minas Gerais e Aluno do Curso de Mestrado em Lazer - Centro de Estudos do Lazer e Recreação - CELAR/UFMG.

Agradeço a Bethânia de Araújo Almeida pelo apoio e leitura deste artigo.

2 Professor Adjunto da Faculdade de Educação - FaE/UFMG; Professor do curso de Mestrado em Lazer na pós-graduação da Escola de Educação Física da UFMG; e Membro do Núcleo de Estudos e Pesquisas do Pensamento Complexo.

${ }^{3}$ Definido como "momento histórico no qual a construção ou reconstrução do espaço se dará com um crescente conteúdo de ciência, de técnicas e de informação" (Ibidem, p. 35). ${ }^{4}$ Segundo Ariès (1978), foi a partir desse momento que surgi o sentimento moderno de infância, onde a atenção especial foi destinada ao espaço privado.

${ }^{5}$ Segundo Kohan (2008), os primeiros nascimentos da palavra infância, baseado em estudos etimológicos, estão "ligados às normas e ao direito, ao domínio da res publica muito mais do que ao âmbito privado ou familiar: Um indivíduo de pouca idade é denominado infans. Esse termo está formado por um prefixo privativo in e fari, 'falar', daí seu sentido de 'que não fala', 'incapaz de falar'. Tão forte é seu sentido originário que Lucrécio emprega ainda o substantivo derivado infantia com sentido de 'incapaz de falar'. Porém, logo infans substantivado - e infantia são empregados no sentido de 'infante', 'criança' e 'infância', respectivamente. De fato, é desse sentido que se geram os derivados e compostos, todos de época imperial, como infantilis, 'infantil'; infanticidium, 'infanticídio', etc' (p. 40). 
${ }^{6}$ Nova redação dada, conforme Emenda Constitucional n ${ }^{\circ} 20$ de 16 de dezembro de 1998. Sobre a idade mínima permitida para o trabalho destacam-se: Constituição Federal, art. $7^{\circ}$, XXXIII; Organização Internacional do Trabalho, Convenção 138; Consolidação das Leis do Trabalho, art. 403.

${ }^{7}$ Convenção sobre Idade Mínima, 1973. Convocada em Genebra pelo Conselho de Administração da Secretaria Internacional do Trabalho e reunida em 6 de junho de 1973, em sua 58 Reunião. Maiores detalhes no site <http://www.oit.org.br/convenção 138>. Acessado em 11 de agosto de 2008.

${ }^{8}$ Segundo a PNAD 2007, do contingente de 44,7 milhões de crianças e adolescentes de 5 a 17 anos de idade, 4,8 milhões estavam trabalhando. De acordo com os dados encontrados, a estimativa apontou redução em relação a 2006, quando existiam, no País, 5,1 milhões de trabalhadores nesta faixa etária. Maiores detalhes podem ser consultados no site <http://www.ibge.gov.br/home>. Acessado em 05/03/2009.

${ }^{9}$ Nessa perspectiva, destacamos: GRACIANI, M. S. S. Pedagogia Social de Rua. 5a. ed. São Paulo: Editora Cortez, 2005; MARQUES, W. E. U. Infâncias (pre)ocupadas: Trabalho Infantil, Família e identidade. Brasília: Plano Editora, 2001; MARTINS, J. S. (Org.). O Massacre dos Inocentes (Org.). São Paulo: Editora Hucitec, 1991; SILVA, M. R. Trama Doce- Amarga: exploração do trabalho infantil e cultura lúdica. São Paulo: HUCITEC, 2003; MARIN, J. O. B. . Trabalho infantil: necessidade, valor e exclusão social. Brasilia/ Goiânia: Plano Editora e Editora UFG, 2006, dentre outros.

${ }^{10}$ Trabalho de campo realizado durante sete dias consecutivos na última semana de junho de 2004. Dados apresentados na Revista Pensar BH - No 12, ano 2006.

${ }^{11}$ Este estudo é fruto da pesquisa realizada no Programa de Educação Tutorial (SESu/ MEC) - PET - Educação Física e Lazer da UFMG, orientado pelo Professor José Alfredo Oliveira Debortoli no período de 2005-2007. Crianças nos Sinais: um olhar sobre o trabalho infantil e as possibilidades e impossibilidades de vivências de lazer nas ruas de Belo Horizonte. Artigo sobre o estudo pode ser visto no site <http://www.eeffto.ufmg.br/ licere/pdf/licereV10N01_a7.pdf>

${ }^{12}$ As vendas ocorriam nos ônibus coletivos, nos bares e nos sinais de trânsito da cidade.

${ }^{13} \mathrm{Na}$ feira de Artesanato da Afonso Pena, considerada maior feira de artesanato a céu aberto da América Latina que ocorre em uma das principais avenidas de Belo Horizonte aos domingos, observou-se uma ação que tem se tornando muito comum. Inúmeras crianças se pintam e se fantasiam de estátuas permanecendo imóveis em lugares estratégicos, antes ocupados por adultos que também exerciam a mesma prática, com a finalidade de arrecadarem dinheiro.

${ }^{14}$ Projeto de Mestrado desenvolvido no Programa de Pós-Graduação da Universidade Federal de Minas Gerais - UFMG - Mestrado Multidisciplinar em Lazer - Centro de Estudos do Lazer e Recreação da UFMG sob a Orientação do Professor Walter Ernesto Ude Marques (Faculdade de Educação da UFMG) e co-orientado pelo Professor José Alfredo Oliveira Debortoli (Escola de Educação Física, Fisioterapia e Terapia Ocupacional da UFMG), intitulado: Nos "Sinais" da Cidade: experiências de infância entre o trabalho e o lazer no espaço urbano.

\section{Referências}

ARROYO, M. A infância interroga a pedagogia. In. SARMENTO, M.; GOUVEA, M.C. (orgs.) Estudos da Infância. Petrópolis: Vozes, 2008, p. 119-140. 
BOURDIEU, Pierre. A Dominação Masculina. 3a. ed. Rio de Janeiro - RJ: Bertrand Brasil, 2003.

BRASIL. Lei 8.069 de 13 de julho de 1990. Estatuto da Criança e do Adolescente. Diário Oficial da Republica Federativa do Brasil, Ministério da Justiça. Brasília, DF, 1990.

BRASIL. Constituição da República Federativa do Brasil. São Paulo: Tecnoprint, 1988.

BULCÃO, I. . A Produção de Infâncias Desiguais: uma viagem na gênese dos conceitos 'criança' e 'menor'. In: Maria Lívia do Nascimento. (Org.). PIVETES: a produção de infâncias Desiguais. Niterói / Rio de Janeiro: Intertexto / Oficina do Autor, 2002, p. 61-73.

CAMPOS, T.; DEBORTOLI, J. A. O. Crianças nos Sinais: um olhar sobre o trabalho infantil e as possibilidades e impossibilidades de vivências do lazer nas ruas de Belo Horizonte. In: Revista Licere, Belo Horizonte, v.10, n.1, abril./2007.

CAMPOS, H. R.; ALVERGA, A. R.. Trabalho infantil e ideologia: contribuição ao estudo da crença indiscriminada na dignidade do trabalho. Estudos em Psicologia, 2001. 227 - 233.

CASTRO, J. A. L.; CASTRO, D. S. L. Aspectos jurídicos da proibição do trabalho infantil e da proteção ao trabalhador adolescente. In: Antônio de Carvalho Neto et al. (Org.). Trabalho infantil: a infância roubada. Belo Horizonte: PUC Minas, 2002, p. 61-77.

CARLOS, A. F. A. Espaço-tempo na metrópole: a fragmentação da vida cotidiana. São Paulo: Contexto, 2001.

DEBORTOLI. J. A. et al. As experiências de infância na metrópole. In: DEBORTOLI, J. A.; MARTINS, M.; MARTINS, S. (Orgs.). Infâncias na metrópole. Belo Horizonte: Editora UFMG, 2008, p. 19-46. 
DEBORTOLI, J. A. O. Com olhos de crianças: a ludicidade como dimensão fundamental da construção da linguagem e da formação humana. In: Revista Licere, Belo Horizonte, v.2, n.1, 1999, p. 105-117.

DIMENSTEIN, Gilberto. Meninas da Noite: a prostituição de meninas-escravas no Brasil. 5a. ed.São Paulo: Ática, 1992.

GRACIANI, M. S. S. Pedagogia Social de Rua. 5a.. ed. São Paulo: Editora Cortez, 2005.

IBGE - INSTITUTO BRASILEIRO DE GEOGRAFIA E ESTATÍSTICA. Pesquisa Nacional por Amostra de Domicílios: indicadores sociais. Rio de Janeiro, 2008.

KOHAN, W. O. Infância e Filosofia In. SARMENTO, M.; GOUVEA, M.C. (orgs.) Estudos da Infância. Petrópolis: Vozes, 2008, p. 40-61.

MACHADO, Lia Zanotta. Masculinidades e violências: Gênero e mal-estar na sociedade contemporânea. In: SCHPUN, Mônica Raisa (Org.). Masculinidades. São Paulo-SP: UNISC, 2004.

MARIN, J. O. B. Os programas de erradicação do trabalho infantil em questão. Revista da UFG: ensino, pesquisa, extensão e cultura, Universidade Federal de Goiás, v. 2, 2004, p. 33-36.

. Trabalho infantil: necessidade, valor e exclusão social.

1. ed. Brasilia/Goiânia: Plano Editora e Editora UFG, 2006.

MARQUES, Walter Ernesto Ude. Infâncias (pre)ocupadas: Trabalho Infantil, Família e identidade. Brasília: Plano Editora, 2001.

MARTINS, J. S. (Coord.) O massacre dos inocentes: a criança sem infância no Brasil. 2. ed. São Paulo: Hucitec, 1993. 
MOURA, E. B. B. Crianças operárias na recém-industrializada São Paulo. In: PRIORE, M. L. M. A História das Crianças no Brasil. 3. ed. São Paulo: Contexto, 2002, p. 259-288.

MUMFORD, L. A Cidade na História. 2v. Belo Horizonte: Itatiaia, 1961.

NOGUEIRA, Paulo Henrique de Queiroz. Identidade Juvenil e Identidade Discente: processos de escolarização no terceiro ciclo da Escola Plural. Belo Horizonte: Faculdade de Educação, 2006. (Tese de Doutorado)

RIZZINI, I. Pequenos trabalhadores do Brasil. In: PRIORE, M. L. M. A História das Crianças no Brasil. 3. ed. São Paulo: Contexto, 2002.

OLIVEIRA, Pedro Paulo. A construção social da masculinidade.Belo Horizonte: UFMG; Rio de Janeiro -RJ: IUPERJ, 2004.

OLIVEIRA, B. As Relações entre conhecimento e valoração no trabalho educativo. In. O trabalho educativo: reflexões sobre paradigmas e problemas do pensamento pedagógico brasileiro. Campinas, SP: Autores Associados, p. 5-23, 1996.

OLIVEIRA, O. O trabalho da criança e do adolescente. São Paulo, LTR; Brasília, DF, 1994.

PASSETTI, E. O menor no Brasil republicano. In: Del Priore, M.. (Org.). História da criança no Brasil. São Paulo: Contexto, 1991, v. 1, p. 146-175.

SANTOS, M. A. C. Criança e criminalidade no início do século. In: PRIORE, M. L. M. A História das Crianças no Brasil. 3. ed. São Paulo: Contexto, 2002, p. 210-230.

SANTOS, M. A urbanização brasileira. 2. Ed. São Paulo: Hucitec, 1994. 
SEABRA, O. C. L. Notas sobre a problemática do espaço da criança na urbanização contemporânea. São Paulo, 2004. 8f. Mimeografado. Texto compartilhado pela autora por ocasião do VI Congresso Brasileiro de Geógrafos, ocorrido em Goiânia, de 18 a 23 e julho de 2004.

SMAAS - SECRETARIA MUNICIPAL ADJUNTA DE ASSISTÊNCIA SOCIAL. O trabalho infanto-juvenil nas ruas de Belo Horizonte: complexidades e desafios. Belo Horizonte. Revista Pensar BH - $\mathrm{N}^{\mathrm{o}}$ 12, ano 2006.

SILVA, M. R. Exploração do trabalho infantil: em busca da cultura lúdica no âmbito da região da cana-de-açúcar do nordeste do Brasil. In: $3^{\circ}$. Congreso Mundial sobre los Derechos de La Ninez y la Adolescência, Barcelona, 2007.

SILVA, M. R. Trabalho infantil ou exploração do trabalho infantil. In: REDIN, Euclides; MÜLLER, Fernanda; REDIN, Marita Martins. (Org.). Infâncias: cidades e escolas amigas das crianças. Porto Alegre: Editora Mediação, 2001, p. 57-75.

\section{Abstract:}

\section{Exploitation of Child Labor, Urban Space and Traffic Signs: tensions between being a child and having to work}

This text aims to encourage discussions concerning the exploitation of child labor in the urban context and its implications regarding the tension between being a child and having to work in order to address the conditions of the presence of a particular childhood, childhood working in metropolis, in particular, the "signs" of transit. Search also raise questions regarding the street as a space for affirmation of manhood, which presents marked by its own codes and temporal boundaries of a warrior ethos, composed of children and young male workers. 
Key words: Childhood. Work. Exploitation of child labor.

Recebido em outubro de 2009. Aceito em maio 2010. 